\title{
ESTUDO DE AUTODEPURAÇÃO: O CASO DO CÓRREGO DO LIMOEIRO, PRESIDENTE PRUDENTE - SP
}

\author{
SELF-PURIFICATION STUDY: THE CASE OF THE LIMOEIRO STREAM, \\ PRESIDENTE PRUDENTE - SP
}

\author{
Tamíris Silva Corrêa, Renata Ribeiro de Araújo \\ 1 Universidade Estadual Paulista - UNESP, Departamento de Planejamento, \\ Urbanismo e Ambiente, Engenharia Ambiental, Presidente Prudente, SP. Agência de \\ fomento: Fundação de amparo à pesquisa do Estado de São Paulo. \\ E-mail: tamirissc@yahoo.com.br
}

RESUMO - Autodepuração é a capacidade que os corpos d'água possuem de recuperar-se de maneira natural, ou seja, sem necessidade de intervenção, após despejo de algum tipo de carga orgânica, mas essa capacidade é limitada e influenciada por alguns fatores. Assim, tal pesquisa objetiva estudar a capacidade autodepurativa do Córrego do Limoeiro (classe 4), localizado no município de Presidente Prudente - SP, após a introdução de uma fonte de poluição, que no caso é o lançamento de efluente tratado. A modelagem matemática utilizada é a Streeter \& Phelps (1925), a qual depende da quantificação de variáveis limnológicas e hidrológicas, o que foi realizado em 5 seções. Os resultados mostraram que corpo d'água tem capacidade suporte para o esgoto tratado que recebe, ou seja, consegue ir recuperando suas características anteriores 'introdução da carga orgânica.

Palavras-chave: Autodepuração; Córrego do Limoeiro; Variáveis Limnológicas; Modelagem Streeter \& Phelps; Capacidade Autodepurativa.

ABSTRACT - Self-purification is the ability of the water bodies have to recover naturally, i.e. without intervention, after receiving some type of organic load, but this capacity is limited and influenced by a few factors. So, this research aims to study the self-purification capacity of Limoeiro Stream (class 4), located in the city of Presidente Prudente $\mathrm{SP}$, after the introduction of a source of pollution, which in this case is the release of treated effluent. The mathematical modeling used is the Streeter \& Phelps (1925), which depends on the quantification of limnological and hydrological variables, which was held in 5 sections. The results showed that the stream has capacity to support the treated sewage which it receives, that is, it can recover gradually its earlier features the introduction of the organic load.

Recebido em: 18/08/2015 Revisado em: 10/09/2015 Aprovado em: 15/09/2015

Keywords: Self-Purification; Limoeiro Stream; Limnological Variables; Streeter \& Phelps Modeling; Self-Purification Capacity. 


\section{INTRODUÇÃO}

Autodepuração é a capacidade que os corpos d'água possuem de recuperar-se de maneira natural, ou seja, sem necessidade de intervenção, após despejo de algum tipo de carga orgânica, mas essa capacidade é limitada e influenciada por alguns fatores. Estudar a capacidade autodepurativa é de extrema importância, já que lançamentos de efluentes que estejam acima dessa capacidade podem comprometer todo o ecossistema aquático, inviabilizando, assim, os usos da água, não só do curso hídrico em pesquisa, mas também dos corpos d'água dos quais ele é afluente.

Para simular a autodepuração são utilizados modelos matemáticos, um dos mais consagrados é o de Streeter \& Phelps (1925). Este modelo tem como interesse definir os impactos e as variações, pelas quais é submetida, em função do tempo e da posição, a concentração de determinada carga de poluentes (SANTOS, 2001). Para aplicar a modelagem é de estrema importância conhecer e quantificar as constantes $k_{1}, k_{2}$ e $k_{d}$.

O primeiro coeficiente $(k 1)$ é o coeficiente de desoxigenação, o qual depende de características do corpo hídrico, como matéria orgânica, temperatura e presença de substâncias inibidoras, bem como depende também das características do efluente que está sendo lançado. Em relação ao coeficiente de remoção da demanda bioquímica de oxigênio efetiva no rio $\left(k_{d}\right)$, Mourão Júnior (2010) explica que, em grande parte das vezes, em condições ambientes, a remoção da DBO resulta em valores maiores do que aqueles determinados laboratorialmente. De acordo com Chapra (1997) (apud MOURÃO JÚNIOR, 2010), isso acontece devido a sedimentação da matéria orgânica e remoção da DBO pelo lodo do fundo; o coeficiente de remoção da DBO efetiva no rio $\left(k_{d}\right)$ inclui estes dois fenômenos de modo que $k_{d}$ (oxidação da DBO no curso d'água) $\geq k_{1}$ (oxidação da DBO em laboratório). E a última constante $\left(\mathrm{k}_{2}\right)$, constante de reoxigenação do corpo d'água, depende da turbulência das águas.

Nesse contexto, , o objetivo da presente pesquisa é analisar o processo de autodepuração de um trecho do Córrego do Limoeiro, localizado no município de Presidente Prudente/SP, utilizando da modelagem Streeter \& Phelps (1925).

\section{METODOLOGIA}

Para viabilizar o desenvolvimento do estudo de autodepuração para o Córrego do Limoeiro, foi realizado o monitoramento das variáveis limnológicas e hidrológicas, no trecho de interesse do Córrego do Limoeiro, de acordo com o que é exposto na Figura 1. 


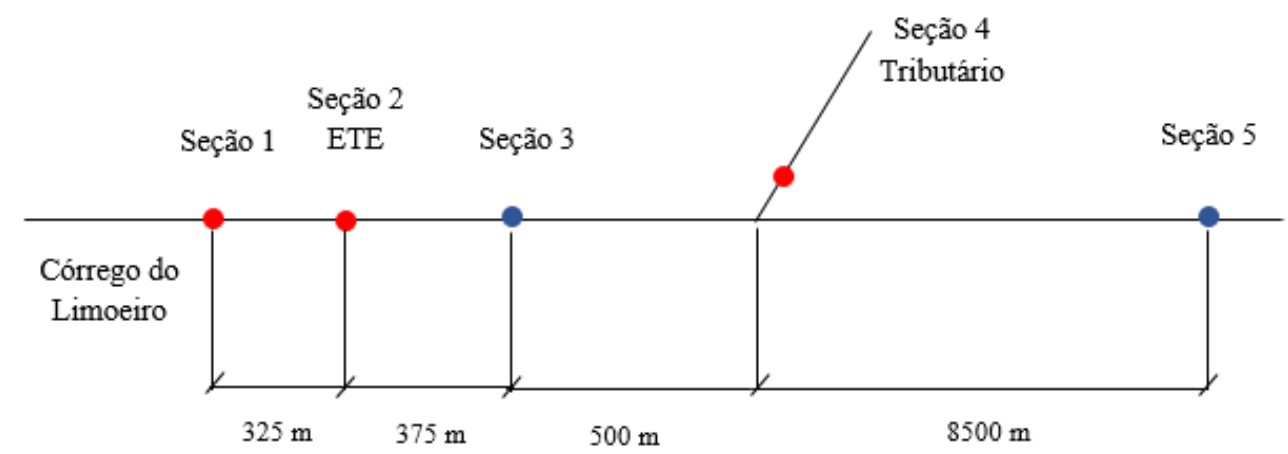

Legenda:

- Seções de entrada

- Seções de controle

Figura 1. Croqui da área de estudo

Fonte: Autor

Segundo a Figura 1, o trecho estudado foi divido em trechos menores. O primeiro trecho teve como seções de entrada as Seções 1 e 2, e seção de controle a Seção 3; o segundo trecho teve como seções de entrada as Seções 3 e 4, e seção de controle a 5. Para as seções de entrada é imprescindível que se obtenha as variáveis Demanda Bioquímica de Oxigênio (DBO), oxigênio dissolvido (OD), temperatura, Área da seção (A) e Vazão (Q). Já para as seções de controle são necessários apenas os dados de OD e DBO. As seções de controle são importantes para que os valores adquiridos com a modelagem sejam comparados aqueles resultantes do monitoramento.

As variáveis foram obtidas da seguinte maneira: para a temperatura, utilizou-se de um termômetro; a DBO foi obtida por metodologia do Standard of Methods (1998); a profundidade, por régua métrica; $\mathrm{o} \mathrm{pH}$, através de Potenciômetro Digital Portátil e o OD, por Oxímetro Digital Portátil. A determinação da vazão foi realizada segundo a metodologia de medição da vazão em rios pelo método do flutuador descrita por Palhares et al. (2007).

Em seguida, foram calculados os coeficientes de desoxigenação $\left(k_{1}\right)$ e o de remoção de DBO efetiva $\left(k_{d}\right)$. Ambos os coeficientes foram retirados da tabela dada por Von Sperling (2007) para corpos d'água recebendo efluente secundário e são de 0,18 para $k_{1}$ e 0,24 para $k_{d}$.

Já para o coeficiente de reoxigenação (k2), os valores numéricos podem ser obtidos das mais distintas formas. No caso das análises de autodepuração no Córrego do Limoeiro, optou-se pela aplicação da formulação de Owens et al. (apud BRANCO, 1978; CHAPRA, 1997), na medida que a sua validade para profundidade $\quad(0,1 m \leq H<0,6 m) \quad$ e 
velocidade do curso d'água $(0,05 \mathrm{~m} / \mathrm{s} \leq V<$ $1,5 \mathrm{~m} / \mathrm{s}$ ) eram compatíveis com as características hidráulicas do curso d'água em questão. Todas as constantes são fornecidas a temperatura de $20^{\circ} \mathrm{C}$, então é necessário que para utilizá-las sejam feitas as compensações para a temperatura obtida no monitoramento, isso foi realizado de acordo com o descrito por Tomaz (2008).

Para a aplicação da modelagem Streeter \& Phelps (1925), os dados foram tabulados em planilhas do software Excel for Windows 2013, segundo metodologia proposta por Von Sperling (2007). A metodologia foi aplicada até $14,8 \mathrm{~km}$, na medida que esta é a extensão do córrego desde o lançamento de esgoto tratado pela Estação de Tratamento de Esgoto (ETE) até a sua confluência com o Rio Santo Anastácio. Após todo o processamento, foram plotados gráficos, também, no software Excel for Windows 2013 e de acordo com a metodologia do mesmo autor.

\section{RESULTADOS}

As constantes utilizadas para a aplicação da modelagem Streeter \& Phelps (1925) podem ser visualizadas na Tabela 1, na qual os coeficientes se referem ao primeiro trecho e ao segundo de estudo.

Tabela 1. Coeficientes utilizados na modelagem Streeter \& Phelps (1925) para o primeiro trecho

\begin{tabular}{ccc}
$\begin{array}{c}\text { Coeficientes de } \\
\text { calibração do modelo }\end{array}$ & Primeiro trecho & Segundo trecho \\
\hline$k_{1}$ & $0,2505 \mathrm{~d}^{-1}$ & $0,2836 \mathrm{~d}^{-1}$ \\
$\mathrm{k}_{\mathrm{d}}$ & $0,3341 \mathrm{~d}^{-1}$ & $0,3782 \mathrm{~d}^{-1}$ \\
$\mathrm{k}_{2}$ & $104,8297 \mathrm{~d}^{-1}$ & $19,8805 \mathrm{~d}^{-1}$ \\
\hline
\end{tabular}

Fonte: Autor

$\mathrm{Na}$ Tabela 2 estão explicitados os

valores obtidos com a amostragem e, posteriormente, em ensaios laboratoriais.

Tabela 2. Dados de OD e DBO obtidos com a aplicação da modelagem Streeter \& Phelps (1925) e em amostragem

\begin{tabular}{ccccc}
\hline Seção & $\begin{array}{c}\text { OD } \\
\text { (mg/L) }\end{array}$ & $\begin{array}{c}\text { DBO } \\
\text { (mg/L) }\end{array}$ & $\begin{array}{c}\text { OD } \\
\text { modelagem }\end{array}$ & $\begin{array}{c}\text { DBO } \\
\text { modelagem }\end{array}$ \\
\hline 1 & 11,20 & 14,00 & ----- & ---- \\
$2^{*}$ & 4,03 & 30,00 & ---- & ---- \\
3 & 7,12 & 18,00 & 7,27 & 24,87 \\
4 & 6,94 & 10,00 & ---- & --- \\
\hline
\end{tabular}


* Os dados referentes à Seção 2, são aqueles do lançamento no córrego, ou seja, dados do efluente tratado.

Fonte: Autor

Como resultados finais da aplicação do modelo matemático, foram obtidos os perfis de OD e DBO, em função da distância, para o Córrego do Limoeiro antes e após a

entrada do efluente tratado, também foram obtidos os perfis de OD e DBO, em função da distância, após a entrada do rio tributário (Figuras 4 e 5).

Figura 2. Perfil de OD em função do tempo para o rio principal



Fonte: Autor

Figura 4. Perfil de OD projeto em função da distância

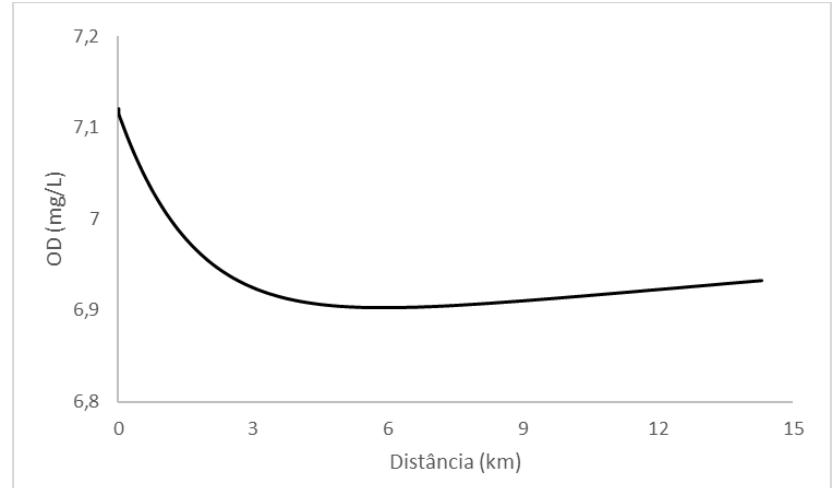

Fonte: Autor

\section{DISCUSSÕES}

A Tabela 1 mostra os valores obtidos para os coeficientes, já corrigidos para a temperatura das águas do corpo d'água $\left(27,2^{\circ} \mathrm{C}\right)$ para o primeiro trecho. De acordo com esta Tabela, nota-se que o valor de $k_{d}$ é
Figura 3. Perfil de DBO em função do tempo para o rio principal

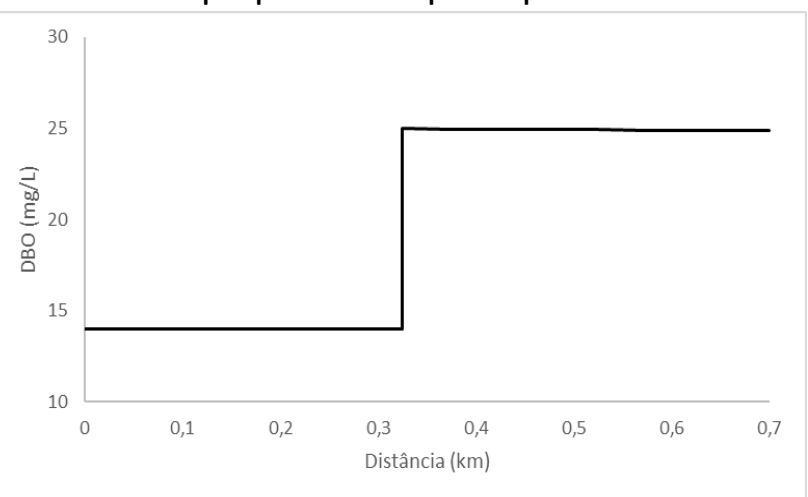

Fonte: Autor

Figura 5. Perfil de DBO projeto em função da distância

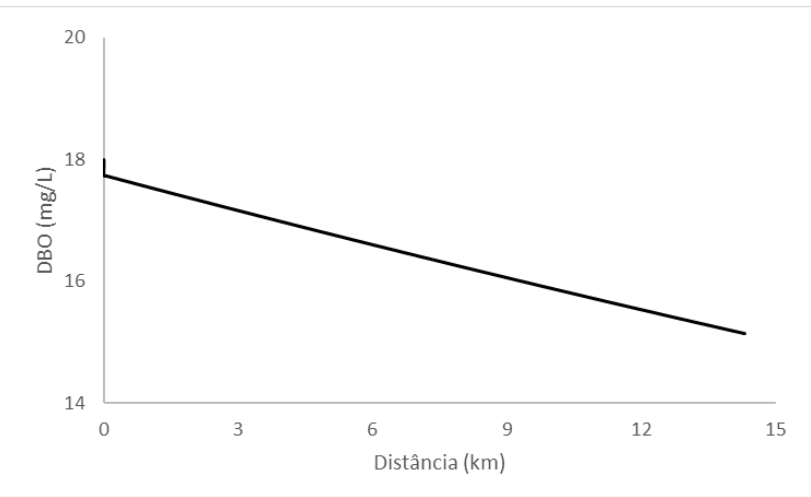

Fonte: Autor

um pouco maior que $k_{1}$, e isso se deve, justamente, ao fato de o coeficiente de remoção da DBO efetiva no rio conter os fenômenos de sedimentação da matéria orgânica e remoção da DBO pelo lodo do fundo. Ainda na Tabela 1, pode ser visto um 
valor elevado para o coeficiente de reoxigenação, o que pode ser explicado pela profundidade do córrego ser pequena, na Seção 1 , não passando de 0,15 metros $(m)$. Portanto, as trocas gasosas ocorrem de maneira intensa, além disso o corpo d'água possui um leito pedregoso, o que promove o turbilhonamento.

Os valores obtidos para os coeficientes, já corrigidos para a temperatura das águas do corpo d'água $\left(29,9^{\circ} \mathrm{C}\right)$, para o segundo trecho podem ser visualizados na Tabela 1. Nela, assim como para o primeiro trecho, o valor de $k_{d}$ é maior do que o de $k_{1}$, pelo mesmo motivo. De acordo com essa Tabela, o valor de $k_{2}$ é elevado, porém não tanto quanto para o trecho 1 , isso acontece porque a Seção 3 é mais profunda do que a Seção 1, chegando a $0,35 \mathrm{~m}$, mas ainda assim os processos de trocas gasosas são significativos.

Em relação à Tabela 2, percebe-se que, para os valores de oxigênio dissolvido, em ambas as Seções de controle (3 e 5), a modelagem predisse valores bastante próximos aos obtidos com a amostragem, pois as diferenças encontradas não chegam a $0,2 \mathrm{mg} / \mathrm{L}$. Para os valores de demanda bioquímica de oxigênio, os valores preditos já não foram tão próximos aos amostrados, as diferenças chegam a quase $6,87 \mathrm{mg} / \mathrm{L}$ para a Seção 3, e 4,16 mg/L para a Seção 5.
As Figuras 2 e 3 evidenciam a concentração de OD e de DBO nas águas do corpo hídrico antes, durante e após o recebimento do efluente tratado pela Estação de Tratamento de Esgotos (ETE). Para melhor visualização dos resultados e comparação com o que ocorre posteriormente, as concentrações de OD e DBO foram consideradas constantes antes do despejo do efluente (desde a Seção 1).

Como pode ser visto na Figura 2, antes do lançamento do efluente tratado, o corpo d'água tem um OD de 11,20 mg/L, já após o despejo de efluente, ocorre uma queda dessa variável limnológica, até valores próximos a $6,28 \mathrm{mg} / \mathrm{L}$. Isso mostra que, mesmo na mistura, ainda, é respeitado o valor de OD mínimo (2 mg/L) para corpos d'água classe 4 , de acordo com o Decreto Estadual $n$ ㅇ 10.755, de 22 de novembro de 1977, e a Resolução Conama 357/05.

Para a DBO (Figura 3), após o lançamento do esgoto tratado, seu valor aumenta significativamente, pois antes do despejo era de $14,00 \mathrm{mg} / \mathrm{L}$, passando para $24,98 \mathrm{mg} / \mathrm{L}$. Passada a mistura, o valor dessa variável começa a decair lentamente, o que torna difícil visualizar alguma mudança pela análise da Figura 3.

A tendência do OD pode ser explicada, segundo Von Sperling (2007), pela relação entre $\left(L_{0} / D_{0}\right)$ e $\left(k_{2} / k_{d}\right)$, na qual $D_{0}$ é a diferença entre a concentração de saturação 
de oxigênio e o OD da mistura e $L_{o}$ é a DBO última da mistura. Quando a relação é $L_{0} / D_{0}<$ $k_{2} / k_{d}$, o tempo crítico, ou seja, o tempo no qual se tem o OD mínimo, pode ser considerado igual a zero e o menor valor dessa variável é obtido no ponto de mistura, coincidindo com o que é mostrado na Figura 2.

Quando o corpo d'água encontra seu tributário, a situação se modifica. É interessante observar que, para a amostragem realizada, o rio tributário estava com um valor de oxigênio dissolvido pouco inferior ao do Córrego do Limoeiro. Consequentemente, como pode ser observado na Figura 4, a concentração de OD caiu com a confluência dos dois cursos hídricos, porém, posteriormente, começou a crescer.

Quanto à DBO, o valor dessa variável, para a amostragem realizada, foi inferior ao valor da do córrego. Assim, segundo a Figura 5, após a confluência dos dois cursos hídricos ocorre uma queda da concentração da demanda bioquímica de oxigênio, posteriormente, essa queda continua ocorrendo lentamente.

Fagá, Vieira e Araújo (2013), estudando a autodepuração do Rio Pirapozinho, observou que após lançamento de efluente tratado, mais especificamente na mistura, o OD, antes de 5,00 mg/L, diminui para um valor bastante baixo, de aproximadamente $1,50 \mathrm{mg} / \mathrm{L}$. Para a DBO, que antes do despejo era de pouco mais de $10,00 \mathrm{mg} / \mathrm{L}$, chega-se a ter quase $90,00 \mathrm{mg} / \mathrm{L}$. Para o Córrego do Limoeiro, os valores não se alteraram tão bruscamente, sendo que para a OD o valor anterior ao lançamento de 11,20 $\mathrm{mg} / \mathrm{L}$ passou para $6,28 \mathrm{mg} / \mathrm{L}$ na mistura, e para a DBO, o valor de $14,00 \mathrm{mg} / \mathrm{L}$ passou para $24,98 \mathrm{mg} / \mathrm{L}$.

\section{CONCLUSÃO}

Os resultados revelam que o corpo d'água encontra-se, em todo o trecho estudado, em conformidade com a sua classificação (classe 4) em relação ao OD, de acordo com o Decreto Estadual no 10.755, de 22 de novembro de 1977, e a Resolução Conama 357/05.

Os valores encontrados com a amostragem e aqueles obtidos com a aplicação da modelagem, para as seções de controle, são bem próximos para o oxigênio dissolvido e mais distantes para a demanda bioquímica de oxigênio. Isso acontece porque existem erros embutidos na amostragem que são de difícil identificação. Além disso, a formulação matemática utilizada modela somente a depleção de oxigênio e reaeração do curso hídrico, sendo que, outros processos podem influenciar na autodepuração. No entanto, esses dois fenômenos são modelados de maneira bastante confiável, o que mostra a 
aplicabilidade do modelo Streeter \& Phelps (1925).

Por último, conclui-se que o Córrego do Limoeiro recebe uma carga de efluente condizente com seu porte, ou seja, tem capacidade de se recuperar ao longo do tempo e do espaço.

\section{REFERÊNCIAS}

ANDRADE, L. N. Autodepuração dos corpos d'água. Vitória, 2010. Disponível em: <http://www.ib.usp.br/revista/node/45>. Acessado em: 20 fev. 2015.

FAGÁ, B. F.; VIEIRA, M. A. S.; ARAÚJO, R. R. Autodepuração do Rio Pirapozinho/SP. $2013 . \quad$ Disponível em: <https://www.abrh.org.br/sgcv3/UserFiles/S umarios/7036fObf46ffOfefd9e30cc8a0a25015 _04 ac8636fd3f323f74b38bdfdf0de2ff.pdf>. Acesso em: 19 jul. 2015.

MOURÃO JÚNIOR, P. R. Aplicação do modelo de autodepuração de qualidade das águas QUAL-UFMG: Estudo de caso sub-bacia do Rio Piracicaba. 2010. 160 f. Dissertação (Mestrado) - Universidade Federal de Ouro Preto, Ouro Preto - MG. Disponível em: <http://www.sustentabilidade.ufop.br/arquiv os/dis2010/Polynice\%20Mourao.pdf $>$.

Acessado em: 21 jan. 2015.

PALHARES, J. C. P. et. al. Medição da vazão em rios pelo método do flutuador. Comunicado Técnico, Concórdia, Julho de $2007 . \quad$ Disponível em: <http://www.infoteca.cnptia.embrapa.br/ bitstream/doc/443939/1/CUsersPiazzonDocu ments455.pdf>. Acessado em: 24 jul. 2015.

SANTOS, A. R. Caracterização morfológica, hidrológica e ambiental da bacia hidrográfica do Rio Turvo Sujo, microrregião de Viçosa, MG. 2001. 143 f. Dissertação (Mestrado) - Universidade Federal de Viçosa,
Viçosa- MG. Disponível em: $<$ http://www.mundogeomatica.

com.br/TesesMonografias/Tese_Site/Tese_D outorado_Prof_Alexandre_Rosa_Santos.pdf> . Acessa do em: 22 jan. 2015.

STREETER, H. W., PHELPS, E. B. A study of the natural purification of the Ohio River. Public Health Bulletin 146, U.S. Washington: Public Health Service, 1925.

TOMAZ, P. Capítulo 1: método simplificado para determinação da qualidade da água em córregos e rios. Autodepuração dos cursos d'água: 2008. Disponível em: <http://www.pliniotomaz.com.br/ downloads/livros/livro_nitrogenio/capitulo01 .pdf>. Acessado em: 24 jul. 2015.

VON SPERLING, M. Estudos e modelagem da qualidade da água e de rios. 1 ed. Belo Horizonte: DESA-UFMG, 2007. v. 7. 